\title{
Density dependence and changes in the carrying capacity of Alaskan seabird populations
}

\author{
Holly F. Goyert ${ }^{\mathrm{a}, *}$, Edward O. Garton ${ }^{\mathrm{a}}$, Brie A. Drummond ${ }^{\mathrm{b}}$, Heather M. Renner ${ }^{\mathrm{b}}$ \\ a Idaho Cooperative Fish \& Wildlife Research Unit, University of Idaho, College of Natural Resources, Dept. of Fish and Wildlife Sciences, Moscow, ID 83843, United States \\ b Alaska Maritime National Wildlife Refuge, U.S. Fish and Wildlife Service, Homer, AK 99603, United States
}

\section{A R T I C L E I N F O}

\section{Article history:}

Received 17 November 2016

Received in revised form 31 January 2017

Accepted 6 February 2017

Available online 23 February 2017

\section{Keywords:}

Population viability analysis

Demographics

K-strategy

Endangered species

Marine catastrophe

Oil spill

\begin{abstract}
A B S T R A C T
Evidence for regulation of animal populations by negative density dependence is ubiquitous across the animal realm, and yet the dynamics of carrying capacity (K) are often overlooked. K acts as a threshold below which population size tends to increase and above which it tends to decrease. Documenting changes in this threshold is particularly important to population viability analysis (PVA). We reconstructed the population sizes of five longlived seabird species in Alaska, USA, and analyzed their population dynamics from the past four decades: Black-legged (Rissa tridactyla) and Red-legged Kittiwakes (R. brevirostris), Common (Uria aalge) and Thick-billed Murres (U. lomvia) and Tufted Puffins (Fratercula cirrhata). We evaluated a set of models that allowed for either density independence or density dependence, with or without a time trend in K. The best approximating models indicated that these seabird populations behaved in a negative density-dependent fashion. K increased significantly for murres, and remained relatively stable for Red-legged Kittiwakes. It decreased significantly (>40\%) for Black-legged Kittiwakes and Tufted Puffins, particularly in the Gulf of Alaska, following the 1989 Exxon Valdez oil spill. Although we have less confidence in the puffin data, our PVA suggests that, in the next 100 years, Tufted Puffins may become extirpated from the few colonies that are monitored in the Gulf of Alaska. Negative density dependence can help to prevent population crashes, but time lags and serial correlation in rates of change could suppress the recovery of contracted populations. Therefore, estimating the magnitude of population fluctuations around a changing carrying capacity is essential to managing and conserving declining populations.
\end{abstract}

(C) 2017 Elsevier Ltd. All rights reserved.

\section{Introduction}

Negative density dependence (hereafter just 'density dependence') has long been recognized as a driving force of population regulation, where carrying capacity (K) limits growth rates (May, 1981; Turchin, 1999). Unfortunately, the widespread use of ceiling models (Morris and Doak, 2002) has led to the misinterpretation of $\mathrm{K}$ as a static upper bound to population size. More accurately, K acts as a negative feedback threshold around which population size fluctuates. When below $\mathrm{K}$, populations tend to increase, and when above $\mathrm{K}$ they tend to decrease. We define $\mathrm{K}$ as a quasi-equilibrium under density dependence, at which population growth rate is 0 (Conroy and Carroll, 2009; Dennis and Taper, 1994; May, 1981; Mills, 2012). The factors that drive population dynamics around $\mathrm{K}$ include competition, predation, disease, and resource limitation, which act on vital rates (e.g., birth and death). Just as habitat quality can change through time, so, too, can the number of individuals that it supports (i.e., K; May, 1981). Ignoring density dependence can lead to uncertain and erroneous inference in

\footnotetext{
* Corresponding author.

E-mail address: hgoyert@uidaho.edu (H.F. Goyert).
}

population projections (Morris and Doak, 2002). Accommodating a dynamic $\mathrm{K}$ is crucial to estimating the extinction risk of imperiled animal populations.

Marine birds are long-lived K-selected colony-breeders, and their populations are regulated primarily by density-dependent processes (Hunt et al., 1986; Wooller et al., 1992). The USA supports the largest number of seabird species of any other nation, and is thus ranked highest in global seabird conservation priority (Croxall et al., 2012). Alaska (AK) contains over one third of the US shoreline, including several Important Bird Areas, and hosts approximately one fifth of seabird species worldwide ( $>70$ species; Smith et al., 2014). Of the 19 breeding species that are monitored at colonies in AK (Dragoo et al., 2015), we evaluated the population dynamics of five focal species: Black-legged (Rissa tridactyla) and Red-legged Kittiwakes (R. brevirostris), Common (Uria aalge) and Thick-billed Murres (U. lomvia) and Tufted Puffins (Fratercula cirrhata). Black-legged kittiwakes and murres have circumpolar distributions, while Tufted Puffin populations are restricted to the North Pacific. The global distribution of Red-legged Kittiwakes is almost exclusively found within the range of this study (apart from the Commander Islands, Russia). They are listed as "Vulnerable" according to the Red List of the International Union for Conservation of Nature (IUCN; BirdLife International, 2015a). This is in contrast to the four 
other study species, which are listed as "Least Concern". Baseline information on these species' trends is of high conservation need, particularly to provide context for a U.S. Fish \& Wildlife Service (USFWS) review of tufted puffins, in response to a 2014 petition for their listing under the Endangered Species Act (ESA).

Our objective was to characterize the status of seabird populations in AK at a regional scale, based on colony-scale surveys dating back to the 1970s. We hypothesized that (1) density dependence drives the population dynamics of all five species (Hunt et al., 1986), and (2) tufted puffins project low probabilities of persistence (given documented declines; Gaston et al., 2009; Piatt and Kitaysky, 2002). We implemented an information-theoretic approach to test for both density independence and density dependence, the latter of which allowed us to estimate K. It was important that we measure changes in $\mathrm{K}$ across the 40-year time-series, for the purpose of explaining observed population fluctuations around estimated trends. This suite of stochastic models fed into a population viability analysis (PVA) to estimate probability of persistence and determine whether declines in $\mathrm{K}$ are likely to result in extinction.

We used a case study to determine the environmental sensitivity of each species' population dynamics. The Exxon Valdez oil spill was a dramatic anthropogenic disturbance that occurred in March 1989, at the start of the pre-breeding season in Prince William Sound. We quantified its effect on the vulnerability or resilience of species in the region. The three study genera were differentially exposed to the oil slick, due to their distinct foraging niches. All are primarily piscivorous but kittiwakes are surface feeders whereas murres and puffins are divers, and the latter forage closer to shore (Denlinger, 2006; Smith et al., 2012). After the oil spill, murres showed higher carcass recovery rates and greater population-level impacts than other species (Piatt and Ford, 1996; Piatt et al., 1990). By incorporating the novel perspective of a dynamic $\mathrm{K}$ into our 40-year time-series, we were able to estimate the magnitude of such impacts on $\mathrm{K}$. This is important in maintaining the population thresholds necessary to buffer catastrophes in the conservation of declining populations. Our analysis offers insight into where future management efforts should be directed to promote population persistence and connectivity of circumpolar seabird species breeding in the North Pacific.

\section{Methods}

\subsection{Data}

Alaskan seabirds inhabit four large marine ecosystems (Fig. 1; Ime.noaa.gov; Koeppen et al., 2015): the Aleutian Islands (AI), Arctic (ARC), Eastern Bering Sea (EBS), and Gulf of AK (GOA). Seabird monitoring data have been collected by a number of organizations (Appendix A) at over 30 sites within these ecoregions, some datasets now reaching 40 years. Until now, these data had not been synthesized across the entire state (Byrd et al., 2008; Byrd et al., 2005; Slater and Byrd, 2009). This is due, at least in part, to the exhaustive methods required to standardize variability in the portion of each population sampled by the monitoring programs. Murres and Black-legged Kittiwakes are relatively common species that breed in conspicuous aggregations on coastal ledges at numerous colonies (Byrd, 1989). As such, monitoring data exist for a significant proportion of these species' Alaskan populations (Table 1). In contrast, Tufted Puffins nest in burrows and are difficult to count on colonies, hence they are monitored at only 8 sites that comprise just one tenth of their Alaskan populations. Our sampling protocols include the use of permanent index plots across years and are designed to reduce uncertainty in the detectability of population trends (see Appendix A and Section 4.4 for further discussion).

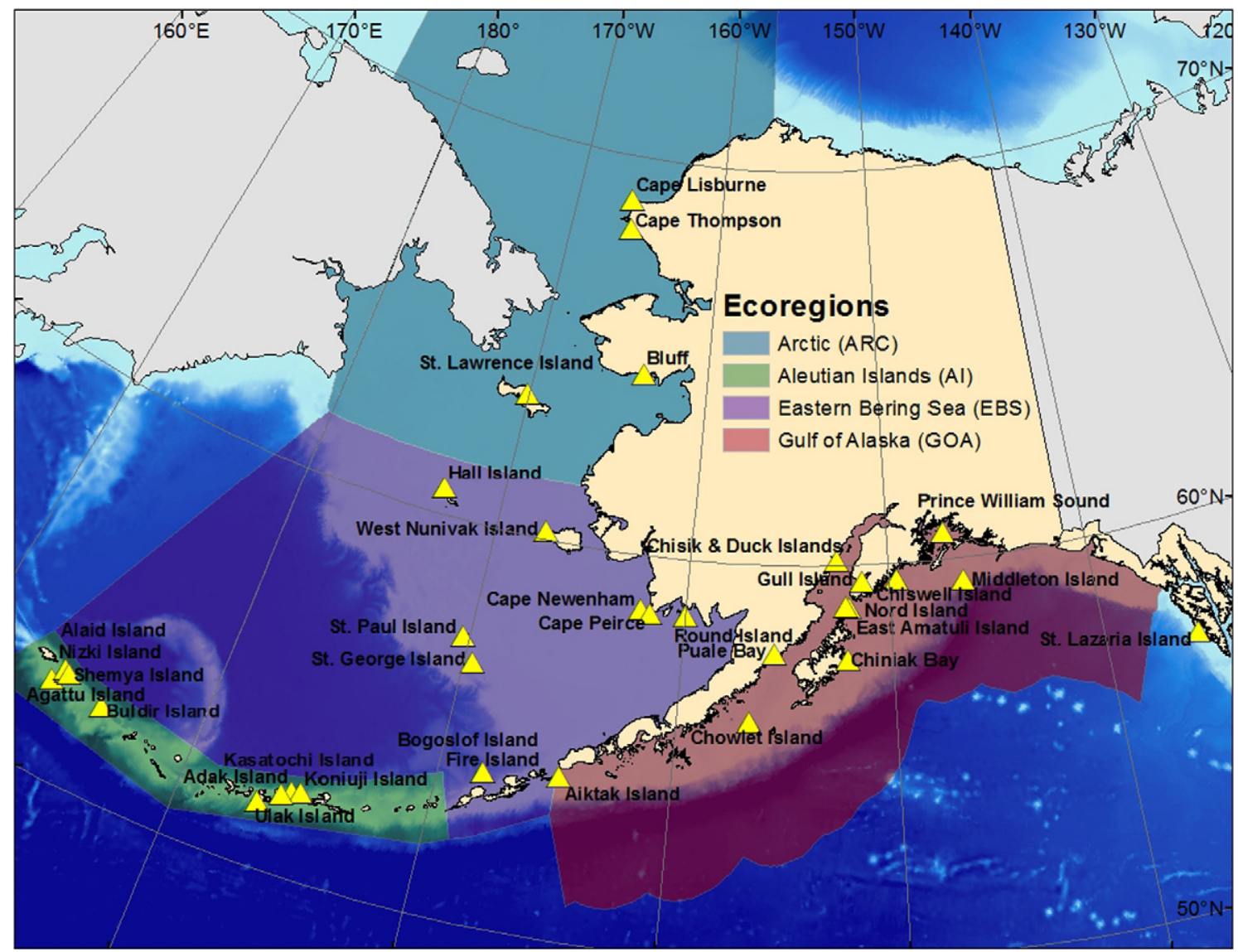

Fig. 1. Sites of monitored seabird colonies in Alaska (yellow triangles), and their corresponding ecoregions. 
Table 1

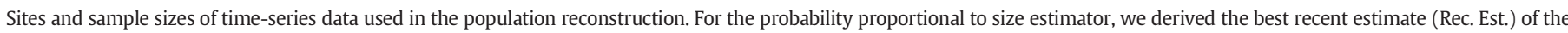

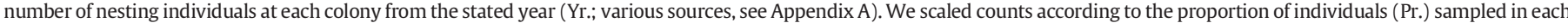

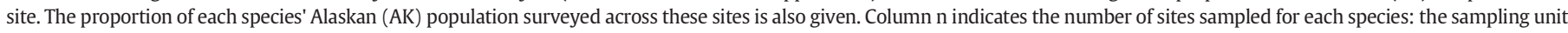

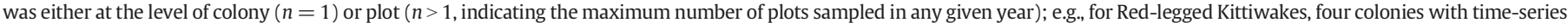

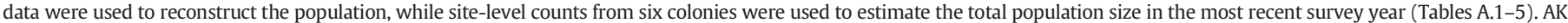
contains four large marine ecosystems: the Aleutian Islands (AI), Arctic (ARC), Eastern Bering Sea (EBS), and Gulf of Alaska (GOA).

\begin{tabular}{|c|c|c|c|c|c|c|c|c|c|c|c|c|c|c|c|c|c|c|c|c|c|}
\hline \multirow[t]{2}{*}{ Rg. } & \multirow[t]{2}{*}{ Site } & \multicolumn{4}{|c|}{ Black-legged kittiwakes } & \multicolumn{4}{|c|}{ Red-legged kittiwakes } & \multicolumn{4}{|c|}{ Common murres } & \multicolumn{4}{|c|}{ Thick-billed murres } & \multicolumn{4}{|c|}{ Tufted puffins } \\
\hline & & Rec. Est. & Yr. & Pr. & $\mathrm{n}$ & Rec. Est. & Yr. & Pr. & $\mathrm{n}$ & Rec. Est. & Yr. & Pr. & $\mathrm{n}$ & Rec. Est. & Yr. & Pr. & $\mathrm{n}$ & Rec. Est. & Yr. & Pr. & $\mathrm{n}$ \\
\hline \multirow[t]{8}{*}{ AI } & Adak Island & & & & & & & & & & & & & & & & & 768 & & 0.20 & 1 \\
\hline & Agattu Island & 7400 & 2003 & 0.22 & 1 & & & & & 6171 & 2003 & 0.42 & 1 & 1543 & 2003 & 0.42 & 1 & & & & \\
\hline & Alaid (Nizki) Island & & & & & & & & & & & & & & & & & 3695 & 1998 & 1.00 & 1 \\
\hline & Buldir Island & 10,901 & 2013 & 0.16 & 31 & 8605 & 2013 & 0.27 & 26 & 1212 & 2013 & 0.08 & 32 & 119,961 & 2013 & 0.20 & 32 & 38,389 & 2014 & 0.06 & 23 \\
\hline & Kasatochi Island & & & & & & & & & 0 & 2002 & 1.00 & 1 & 0 & 2002 & 1.00 & 1 & & & & \\
\hline & Koniuji Island & 3321 & 2010 & 1.00 & 1 & 8 & 2010 & 1.00 & 17 & 1433 & 2010 & 1.00 & 17 & 4299 & 2010 & 1.00 & 17 & & & & \\
\hline & Shemya Island & & & & & & & & & & & & & & & & & & & & \\
\hline & Ulak Island & & & & & & & & & 381 & 2015 & 1.00 & 7 & 1522 & 2015 & 1.00 & 6 & & & & \\
\hline \multirow[t]{4}{*}{ ARC } & Bluff & 7011 & 2008 & 0.08 & 10 & & & & & 47,812 & 2007 & 0.07 & 14 & & & & & & & & \\
\hline & Cape Lisburne & 26,627 & 2013 & 0.16 & 17 & & & & & 133,947 & 2013 & 0.13 & 17 & 327,940 & 2013 & 0.13 & 17 & & & & \\
\hline & Cape Thompson & 8546 & 1995 & 0.26 & 1 & & & & & 4884 & 1995 & 0.57 & 1 & 3838 & 1995 & 0.57 & 1 & & & & \\
\hline & St. Lawrence Island & & & & & & & & & 216,047 & 2004 & 0.00 & 1 & 95,642 & 2004 & 0.00 & 1 & & & & \\
\hline \multirow[t]{9}{*}{ EBS } & Bogoslof Island & & & & & & & & & & & & & & & & & 11,398 & 2004 & 0.03 & 5 \\
\hline & Cape Newenham & 19,972 & 1997 & 0.14 & 21 & & & & & 25,140 & 1997 & 0.24 & 21 & & & & & & & & \\
\hline & Cape Peirce & 8499 & 2014 & 0.25 & 35 & & & & & 6676 & 2014 & 0.41 & 35 & & & & & & & & \\
\hline & Fire Island & & & & & & & & & & & & & & & & & & & & \\
\hline & Hall Island & 6381 & 2012 & 0.01 & 1 & & & & & 57,555 & 2012 & 0.04 & 1 & 143,142 & 2012 & 0.01 & 1 & & & & \\
\hline & Round Island & 70,802 & 2014 & 0.00 & 5 & & & & & 130,997 & 2014 & 0.01 & 5 & & & & & & & & \\
\hline & St. George Island & 70,375 & 2014 & 0.03 & 59 & 235,624 & 2014 & 0.02 & 59 & 218,046 & 2014 & 0.02 & 59 & $1,513,148$ & 2014 & 0.02 & 59 & & & & \\
\hline & St. Paul Island & 22,321 & 2014 & 0.10 & 27 & 1400 & 2014 & 0.11 & 27 & 11,658 & 2014 & 0.15 & 27 & 65,641 & 2014 & 0.13 & 27 & & & & \\
\hline & West Nunivak Island & 19,518 & 1998 & 0.08 & 1 & & & & & 130,994 & 1998 & 0.03 & 1 & & & & & & & & \\
\hline \multirow[t]{12}{*}{ GOA } & Aiktak Island & & & & & & & & & 1228 & 2014 & 0.88 & 10 & 661 & 2014 & 1.00 & 10 & 115,353 & 2014 & 0.01 & 10 \\
\hline & Chiniak Bay & 12,251 & 2004 & 1.00 & 1 & & & & & & & & & & & & & & & & \\
\hline & Chisik \& Duck Islands & 21,916 & 1999 & 0.03 & 1 & & & & & 12,485 & 1999 & 0.01 & 1 & & & & & & & & \\
\hline & Chiswell Island & & & & & & & & & 1810 & 1998 & 1.00 & 1 & & & & & & & & \\
\hline & Chowiet Island & 18,648 & 2014 & 0.03 & 9 & & & & & 392,405 & 2014 & 0.02 & 12 & 12,136 & 2014 & 0.01 & 10 & & & & \\
\hline & East Amatuli Island & 31,263 & 1999 & 0.01 & 1 & & & & & 31,297 & 1999 & 0.20 & 1 & & & & & 38,495 & 2014 & 0.00 & 1 \\
\hline & Gull Island & 12,690 & 2000 & 0.12 & 1 & & & & & 7742 & 2000 & 0.05 & 1 & & & & & & & & \\
\hline & Middleton Island & 6677 & 2008 & 1.00 & 1 & & & & & 2008 & 2007 & 0.75 & 1 & 20 & 2007 & 0.75 & 1 & & & & \\
\hline & Nord Island & & & & & & & & & 16,663 & 1999 & 1.00 & 1 & & & & & & & & \\
\hline & Prince William Sound & 38,354 & 2014 & 1.00 & 1 & & & & & & & & & & & & & 5198 & 1998 & 1.00 & 1 \\
\hline & Puale Bay & 1034 & 2012 & 1.00 & 1 & & & & & 3460 & 2014 & 0.52 & 1 & 182 & 2014 & 0.52 & 1 & & & & \\
\hline & St. Lazaria Island & & & & & & & & & 2579 & 2014 & 0.22 & 9 & 1105 & 2014 & 0.22 & 9 & 7306 & 2011 & 0.01 & 8 \\
\hline AK & & 526,064 & & 0.38 & & 247,300 & & 0.99 & & $1,464,796$ & & 0.38 & & $2,290,781$ & & 0.77 & & 322,880 & & 0.09 & \\
\hline
\end{tabular}

We considered two principal criteria for processing population data. First, population reconstructions for each species required data on annual rates of change, which we derived from systematically sampled counts across 40 years (hereafter referred to as 'time-series data'). Second, the PVA required proper scaling of those time-series to represent total population size across our study area. For the latter, we implemented a probability proportional to size (PPS) estimator (Scheaffer et al., 1996), using the best available census data (hereafter referred to as 'best colony estimates'). These estimates came from a variety of sources (see Appendix A and Tables A.1-5), primarily the Alaska Maritime National Wildlife Refuge (AMNWR) and the Beringian Seabird Colony Catalog database (BSCC). They allowed us to scale the time-series data from plot to colony-level, and from colony to site-level population size (e.g., where a site is a whole island comprised of either multiple index plots or a colony-wide census; Appendix A).

We compiled time-series count data from 33 monitored sites throughout the state of AK (Table 1, Fig. 1, Appendix A, Tables A.1-5). For kittiwakes and murres, counts consisted of breeding-age adults (all murre and most kittiwake datasets) or nests (two Black-legged Kittiwake datasets) observed at breeding colonies. For puffins, counts were derived from numbers of burrow entrances in small index plots at breeding colonies (Appendix A). We were interested in the total abundance of breeding birds for each focal species, but we could only count (or estimate based on burrow counts for puffins) the number of birds attending a nest that were of breeding age. Therefore, these data provide inference to the minimum number of nesting individuals across our study sites, which we refer to as the "total population size" (Garton et al., 2011).

\subsection{Population reconstruction}

Our population reconstruction is based upon methods developed for upland game species and used to review the listing status of Greater Sage Grouse (Centrocercus urophasianus) under the ESA (Garton et al. 2011; Garton et al., 2016). Using historical 'best colony estimates' (Appendix A), we derived 'best recent estimates': the latter allowed us to calculate a probability proportional to size (PPS) estimator (Scheaffer et al., 1996) for our study species in the most recent year of the time-series (2013 for Red-legged Kittiwakes and 2014 for all other species). PPS offers an accurate, precise, and unbiased method of appropriately weighting different colony sizes to prevent overrepresentation from extremely large population counts. Without affecting annual rates of change derived from systematic sampling, it allowed us to scale the time-series to estimates of population size across all colonies ever surveyed within the 33 sites (Appendix A). To project these estimates to the full extent of AK, under the assumption of even sampling, we may divide these values by the proportion sampled of the entire state (Table 1).

In the most recent year of the time-series, we set the PPS estimate (of population size and variance) as the baseline for rebuilding the population backwards through time. For the remaining years, we reconstructed the population by calculating annual rates of change from 
weighted count data (Appendix A). Because most colonies were sampled every second or third year, we imputed the scaled raw counts across 2- or 3-year gaps by calculating the mean rates of change across those missing years. We followed Garton et al. $(2011,2016)$ in estimating the rate of change parameters, except that counts (and their variances) were weighted such that imputed values contributed less than realized values. Only paired counts at colonies sampled in both year $t$ and the following year $t+1$ were used to estimate the annual finite rate of change $\left(\hat{\lambda}_{t}\right)$ and its reciprocal $\left(\hat{\theta}_{t}\right.$, the size of the population relative to the previous year). To reconstruct population size along the time-series, we multiplied the PPS estimate from the most recent year by $\hat{\theta}_{t}$ and continued this iteration sequentially, moving backwards through each previous year. We converted the estimated finite rates of change to instantaneous rates of change $\left(\hat{r}_{t}=\ln \hat{\lambda}_{t}\right)$ to model the population dynamics of each species.

\subsection{Information-theoretic modeling framework}

We evaluated a candidate set of 21 models for each species, across all of AK, as well as across each ecoregion. The null model described density-independent exponential growth with process error (EGPE), and accommodated stochastic process variation around a constant trend; we also allowed that trend to change through time. To test for linear and log-linear density dependence, we implemented discrete time, stochastic Ricker and Gompertz models, respectively (Garton et al., 2011; Garton et al., 2016). We tested a Gompertz state-space model (Dennis et al., 2006) to find minimal estimates of observation error (over $20 \%$ smaller than process noise), and thus proceeded with a single error term.

We allowed for an association between time (up to 38 years, starting at year $t=0$ ) and instantaneous rate of growth, which is analogous to a constant increasing or decreasing time trend in $\mathrm{K}, \beta t$. For example, using the Ricker model,

$\hat{r}_{t}=\mu+\alpha N_{t-\Delta}+\beta t+\varepsilon$,

where $\mu$ is intercept, or the mean rate of change. The density-dependent term $\left(\alpha N_{t-\Delta}\right.$, where $\left.\alpha<0\right)$ incorporates lags $\Delta=0,1$ or 2 and allows rates of change to depend on the population size from the current year $\left(N_{t}\right)$, or from delays of one year $\left(N_{t-1}\right)$, or two years in the past $\left(N_{t-2}\right)$. Process error is represented by $\varepsilon \sim \operatorname{Normal}(0, \sigma)$. We additionally tested for a nonlinear (e.g., asymptotic) effect of time (base $\gamma$ ) on $\mathrm{K}$ with a power model, as follows:

$\hat{r}_{t}=\mu+\alpha N_{t-\Delta}+\gamma^{-t}+\varepsilon$.

We conducted all our analyses in $\mathrm{R}$ (R Development Core Team, 2014), and for the nonlinear model used the starting values $\mu=0$, $\alpha=0$, and $\gamma=1$ in function nls. We estimated $\mathrm{K}$ by setting $\hat{r}_{t}=0$ and solving for $N_{t}$ (Garton et al., 2011; Garton et al., 2016). The relative support of the models in the candidate set were compared with the small-sample corrected Akaike information criterion (AICc). We present results from the most competitive models $(\triangle \mathrm{AICc}<2$; Burnham and Anderson, 2002) of the 21 candidates (with or without density dependence, a lag in density dependence, a constant, trending, or nonlinear effect of time on $\mathrm{K}$ ).

\subsection{Analysis of ecoregions}

For the subset of colonies that corresponded to each of the four ecoregions, we evaluated the same candidate set of 21 models used for each species across AK. For the longer time-series that started in the 1970s (Black-legged Kittiwakes and Common Murres in the GOA and ARC), we additionally tested for a population effect of the 1989 Exxon Valdez oil spill. Oil reportedly persisted in the region until 1992 (Peterson et al., 2003), therefore we evaluated whether changes in $\mathrm{K}$ during this period (1989-1992) differed from those occurring throughout the rest of the time-series. We allowed for an interaction between this period and an annual time trend in $\mathrm{K}$, in addition to the main effects of these two terms (period and year). We evaluated the resulting candidate set of 42 models for Black-legged Kittiwakes and Common Murres in the GOA and ARC. For the purpose of consistency between species and ecoregions, we conducted the PVA using only the candidate set of 21 models that allowed for a time trend in $\mathrm{K}$ (see below).

We tested for autocorrelation in the residuals of the top models per region (using the acf function in $\mathrm{R}$ ) and found that it was not significant, so there was no need to model autocorrelation explicitly. We compared the residuals from the model that had the highest weight summed across all candidate sets (i.e., the Gompertz model with the nonlinear time trend), by running a between-species correlation matrix for each region. This allowed us to infer whether demographic and/or environmental factors extraneous to these models might be affecting each species similarly or differently within each region.

The limited global distribution of Red-legged Kittiwakes was concentrated on the Pribilof Islands (St. George and St. Paul, EBS), which were sampled every three years, in contrast to Buldir (AI), which was sampled every two years; Koniuji had low counts and was sampled annually for under a decade. Therefore, we ran an ad-hoc analysis to investigate potential sampling influences on the identification of 2-year density-dependent time lags. Using the raw counts at each colony (except Koniuji), we calculated rates of change across these 2- or 3-year gaps, without imputation. Although this left only five data points for the three colonies, we evaluated the five simplest models (EGPE, Gompertz and Ricker, the latter two with and without a time trend in K).

\subsection{Population viability analysis}

We conducted a PVA for the populations showing declines (kittiwakes and tufted puffins). To evaluate short- and long-term probability of persistence, we simulated population forecasts for each species 30 and 100 years into the future, starting with the last year of abundance from the population reconstruction. First, we conducted a parametric bootstrap in $\mathrm{R}$, allowing for random normal process variation, to get a measure of uncertainty. We used the fitted parameter estimates from the candidate set of 21 models, to project each population into 3000 replicate stochastic abundance trajectories per model. Next, we estimated the probability of persistence as the proportion of times that the population fell below two thresholds of quasi-extinction: 50 and 500 individuals. These conventional values represent the effective population size $\left(\mathrm{N}_{\mathrm{e}}\right)$ of adults (both sexes) attending their nests (Franklin, 1980; Garton et al., 2011; Garton et al., 2016; Soulé, 1980). We model averaged the results from our candidate set of models, so as to weight each by its relative importance (i.e., models with lower AICc values were assigned more weight; Burnham and Anderson, 2002).

\section{Results}

Across the state of AK (Tables 2, B.1) and within each ecoregion (Table B.2), the top models of the reconstructed populations expressed significant density dependence in all five focal species (Fig. 2).

\subsection{Black-legged kittiwakes}

The most descriptive model of Black-legged Kittiwakes across AK was the Gompertz model with a nonlinear time trend in $\mathrm{K}$ (Table 2, Fig. 2a). Annual growth rates were negatively dependent on the log of population size and mean growth rates $(\mu)$ were higher than those of the other species. K for Black-legged Kittiwakes was estimated at 504,947 in 1976 and 293,862 in 2013, suggesting a 41.8\% decline across those 38 years.

Models of the reconstructed populations from each ecoregion suggested that the GOA, AI, and, to a lesser extent, the EBS, were the source 
Table 2

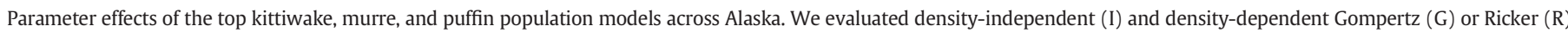

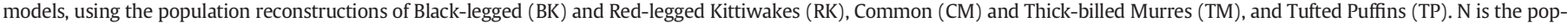

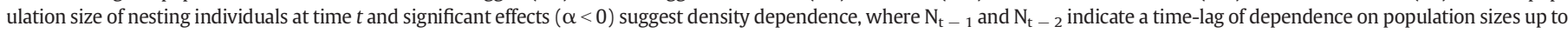

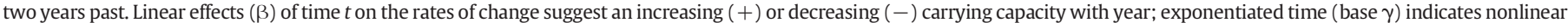

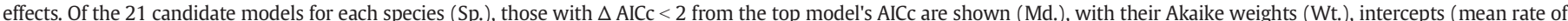
change, $\mu$ ), and error terms $(\sigma)$. For the candidate set corresponding to $95 \%$ of model weight, see Table B.1.

\begin{tabular}{|c|c|c|c|c|c|c|c|c|c|c|c|c|c|}
\hline Sp. & Md. & AICc & Wt. & $\mu$ & $\alpha \mathrm{N}_{\mathrm{t}}$ & $\alpha \ln \left(\mathrm{N}_{\mathrm{t}}\right)$ & $\alpha \mathrm{N}_{\mathrm{t}-1}$ & $\alpha \ln \left(\mathrm{N}_{\mathrm{t}-1}\right)$ & $\alpha N_{t}-2$ & $\alpha \ln \left(\mathrm{N}_{\mathrm{t}}-2\right)$ & $\beta t$ & $\gamma^{\mathrm{t}}$ & $\sigma$ \\
\hline $\mathrm{BK}$ & G & -61.1 & 0.70 & $9.21^{* * *}$ & & $-0.78^{* * *}$ & & & & & & $1.015^{* * *}$ & 0.096 \\
\hline RK & G & -49.6 & 0.19 & $3.93^{* *}$ & & & & & & $-0.32^{* *}$ & & & 0.081 \\
\hline RK & $\mathrm{R}$ & +0.3 & 0.17 & $0.30^{* *}$ & & & & & $-1.29 \mathrm{E}-06^{* *}$ & & & & 0.082 \\
\hline RK & $G$ & +1.0 & 0.12 & $3.39^{*}$ & & & & & & $-0.35^{* *}$ & & $1.003^{* * *}$ & 0.079 \\
\hline RK & G & +1.0 & 0.12 & $4.38^{* *}$ & & & & & & $-0.35^{* *}$ & -0.003 & & 0.079 \\
\hline RK & $\mathrm{R}$ & +1.5 & 0.09 & $-0.63^{* * *}$ & & & & & $-1.41 \mathrm{E}-06^{* *}$ & & & $1.003^{* * * *}$ & 0.079 \\
\hline RK & $\mathrm{R}$ & +1.5 & 0.09 & $0.36^{* *}$ & & & & & $-1.41 \mathrm{E}-06^{* *}$ & & -0.003 & & 0.079 \\
\hline $\mathrm{CM}$ & $G$ & -70.1 & 0.27 & $6.14^{* *}$ & & $-0.46^{* *}$ & & & & & $0.007^{* *}$ & & 0.085 \\
\hline $\mathrm{CM}$ & G & +0.4 & 0.22 & $4.87^{*}$ & & $-0.44^{* *}$ & & & & & & $0.994^{* * *}$ & 0.086 \\
\hline $\mathrm{CM}$ & $\mathrm{R}$ & +1.2 & 0.15 & $0.33^{* *}$ & $-4.89 \mathrm{E}-07^{* *}$ & & & & & & $0.006^{*}$ & & 0.087 \\
\hline $\mathrm{CM}$ & $\mathrm{R}$ & +1.4 & 0.13 & $-0.68^{* * * *}$ & $-4.74 \mathrm{E}-07^{* *}$ & & & & & & & $0.995^{* * *}$ & 0.087 \\
\hline TM & $\mathrm{R}$ & -104.7 & 0.12 & $0.20^{* *}$ & & & $-1.54 \mathrm{E}-07^{*}$ & & & & 0.004 & & 0.054 \\
\hline $\mathrm{TM}$ & $\mathrm{R}$ & +0.2 & 0.11 & $-0.81^{* * *}$ & & & $-1.46 \mathrm{E}-07^{*}$ & & & & & $0.997^{* * *}$ & 0.054 \\
\hline TM & $\mathrm{R}$ & +0.5 & 0.10 & $0.19^{* *}$ & & & & & $-1.54 \mathrm{E}-07^{*}$ & & 0.004 & & 0.054 \\
\hline TM & $\mathrm{R}$ & +0.7 & 0.09 & $-0.81^{* * *}$ & & & & & $-1.46 \mathrm{E}-07^{*}$ & & & $0.997^{* * *}$ & 0.055 \\
\hline $\mathrm{TM}$ & $\mathrm{R}$ & +0.8 & 0.08 & $0.10^{*}$ & & & $-5.55 \mathrm{E}-08^{*}$ & & & & & & 0.056 \\
\hline TM & $\mathrm{R}$ & +1.1 & 0.07 & $0.10^{*}$ & & & & & $-5.28 \mathrm{E}-08^{*}$ & & & & 0.057 \\
\hline TM & G & +1.7 & 0.05 & 1.13 & & & & -0.08 & & & & & 0.057 \\
\hline $\mathrm{TP}$ & G & -59.9 & 0.13 & 3.83 & & -0.29 & & & & & & & 0.060 \\
\hline TP & $\mathrm{R}$ & +0.1 & 0.12 & 0.29 & $-5.90 \mathrm{E}-07$ & & & & & & & & 0.060 \\
\hline ТP & G & +0.2 & 0.12 & $4.96^{*}$ & & $-0.38^{*}$ & & & & & -0.003 & & 0.056 \\
\hline TP & G & +0.2 & 0.12 & 3.93 & & $-0.37^{*}$ & & & & & & $1.003^{\text {**** }}$ & 0.057 \\
\hline TP & $\mathrm{R}$ & +0.4 & 0.11 & $0.41^{*}$ & $-7.66 \mathrm{E}-07^{*}$ & & & & & & -0.003 & & 0.057 \\
\hline TP & $\mathrm{R}$ & +0.4 & 0.11 & $-0.60^{* *}$ & $-7.62 \mathrm{E}-07^{*}$ & & & & & & & $1.003^{\text {*** }}$ & 0.057 \\
\hline TP & I & +1.1 & 0.08 & 0.00 & & & & & & & & & 0.065 \\
\hline
\end{tabular}

*** $p<0.001$.

** $p<0.01$

$* p<0.05$

of Black-legged Kittiwake declines (Table B.2, Fig. 3a). In contrast, the size of colonies in the ARC increased. The top model for the GOA suggested a significant drop in $\mathrm{K}$ of $62.1 \%(p<0.01)$ across the time-series (399,689 to $151,547,1976-2013$ ), and of $82.3 \%$ during the four years following the Exxon Valdez oil spill (389,426 to 68,790, 1989-1992; Fig. 4). Residuals from the nonlinear Gompertz model for Black-legged kittiwakes correlated positively with those of Common Murres in the ARC, Thick-billed Murres in the AI, and Red-legged Kittiwakes in the EBS (Table C.1).

Despite their population declines, the PVA suggested that Black-legged Kittiwakes have a high probability of persistence $(>99.5 \%$, $\mathrm{SE}<0.5 \%$ ) across $\mathrm{AK}$ and in the GOA, over the next 100 years. In the EBS, they have a low probability of extirpation in the next 100 years $\left(\mathrm{N}_{\mathrm{e}}<50,9.9 \%, \mathrm{SE}=3.1 ; \mathrm{N}_{\mathrm{e}}<500,11.88 \%\right.$, $\left.\mathrm{SE}=3.8\right)$. Over that same timeframe in the AI, they have a $45.8 \%$ chance of falling below 50 individuals ( $\mathrm{SE}=11.2$ ), and a $48.3 \%$ chance of falling below 500 individuals $(\mathrm{SE}=11.86)$.

\subsection{Red-legged kittiwakes}

Across the two ecoregions where Red-legged Kittiwakes breed, the six competing models (Table 2) all suggested that rates of change related negatively to the population size from two years in the past (particularly in the Pribilof Islands, EBS; Table B.2). The top model estimated K at 231,061 across 26 years (1987-2012; Fig. 2b). This is despite a recent 6 -year decrease from an estimated population size of 328,283 individuals in 2008 to 175,793 in 2013 (46.5\%). K remained constant at Buldir Island (AI). However, following population declines in the EBS, 2000 marked an eight-year recovery in the population size of Red-legged Kittiwakes. This led to the most competitive models estimating $\mathrm{K}$ to be constant or increasing with time in the EBS (Table B.2). Our ad-hoc analysis of raw counts indicated a significant negative relationship between rates of change and population size at St. George (sampled every three years), meaning that the 2-year lag is likely attributed (at least in part) to that island's sampling regime. Residuals from the nonlinear Gompertz model for Red-legged kittiwakes correlated positively with those of Black-legged Kittiwakes in the Pribilofs (EBS), and Common Murres across AK, particularly in the EBS.

Across AK in the next 100 years, Red-legged Kittiwakes have a 15.0\% probability ( $\mathrm{SE}=4.0$ ) of falling below 50 individuals and a $35.9 \%$ probability ( $\mathrm{SE}=9.5$ ) of falling below 500 . Over that same timeframe, they are not likely to become extirpated from the EBS ( $0 \%$ chance that $\mathrm{Ne}<50$ or 500 ). However, in the AI they are $36.7 \%$ likely ( $\mathrm{SE}=12.1$ ) to fall below 50 individuals and $37.2 \%$ likely $(\mathrm{SE}=12.3)$ to fall below 500 .

\subsection{Common murres}

The Gompertz model with an annual time trend in $\mathrm{K}$ was the most competitive for Common Murres across AK (Table 2, Fig. 2c). It suggested that the population was density-dependent, while $\mathrm{K}$ increased significantly, at a rate of $1.5 \%$ annually. The Gompertz model with an effect of year estimated that $K$ was 678,594 in 1976 and 1,169,563 in 2013, which was a $72.4 \%$ increase across those 38 years. Colonies in the ARC, AI, and GOA shared these increases (Table B.2, Fig. 3c). Despite a $22.4 \%$ decrease in population size of Common Murres in the GOA from 1989 to 1992, the most competitive models suggested that the oil spill did not have a significant effect on $\mathrm{K}$. Residuals from the nonlinear Gompertz model for Common Murres correlated positively with those of all the other species: Thick-billed Murres across AK, particularly in the AI and GOA; Black-legged Kittiwakes in the ARC; Red-legged Kittiwakes across AK, particularly in the EBS; and Tufted Puffins in the AI.

\subsection{Thick-billed murres}

The Ricker model with an increasing time trend in $\mathrm{K}$ was the best of seven competing models for Thick-billed Murres across AK (Table 2, Fig. 2d). It suggested that rates of change were negatively dependent 


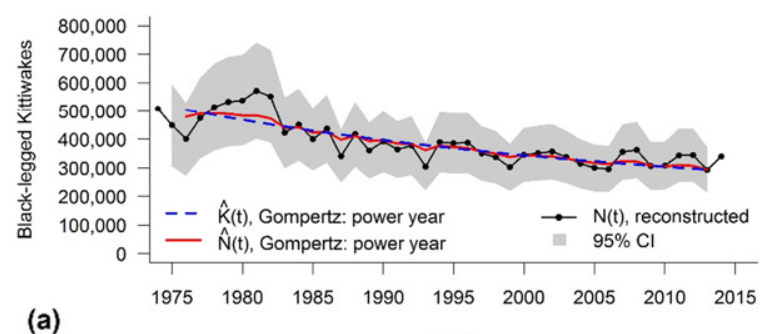

(a)

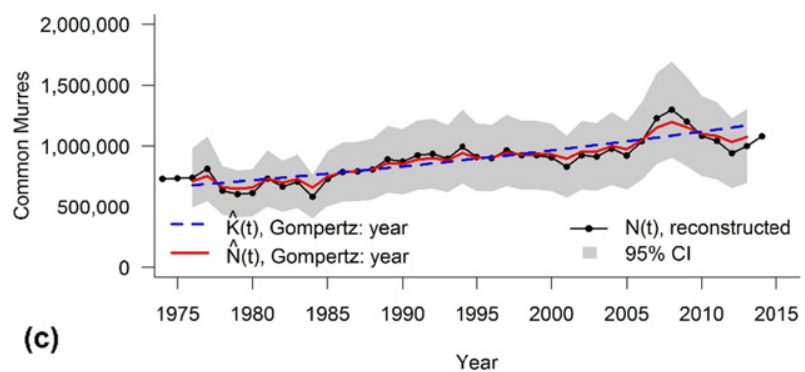

(c)

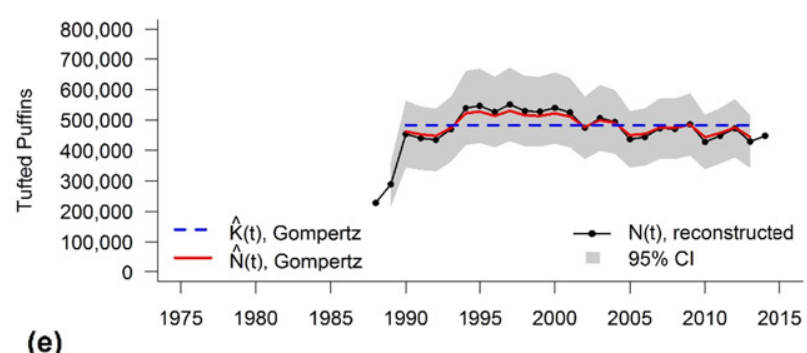

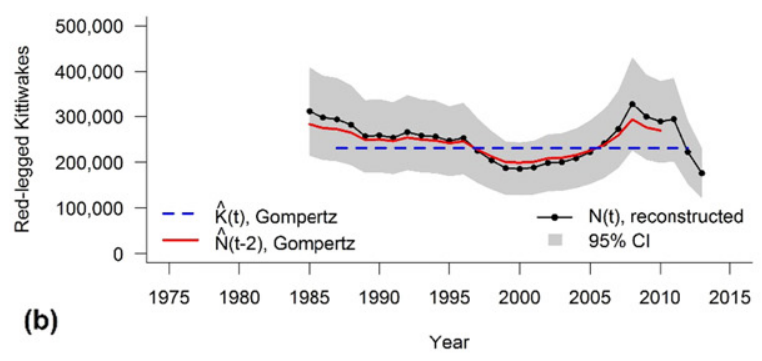

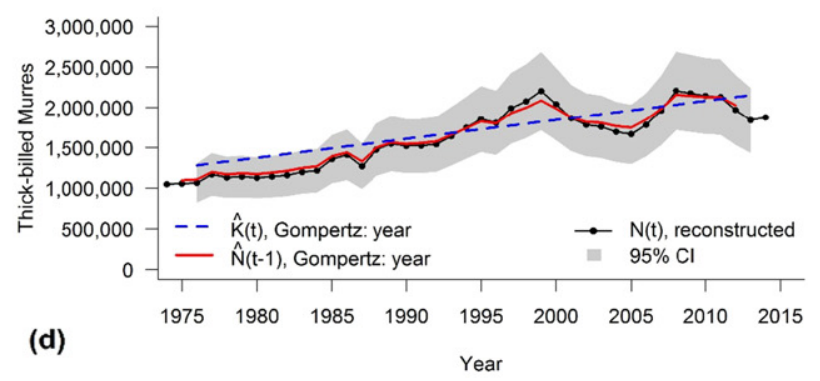

Year

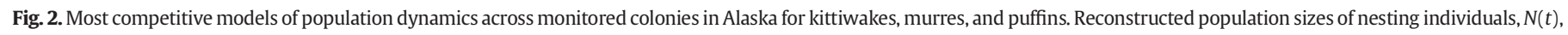

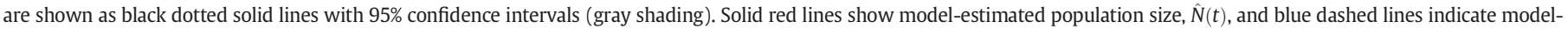

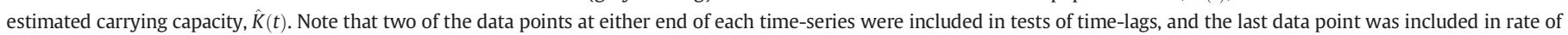
change calculations. All species demonstrated density dependence: (a) Black-legged and (b) red-legged kittiwakes, (c) Common and (d) thick-billed Murres, and (e) tufted puffins.

on the population size from the previous year. $\mathrm{K}$ was estimated at $1,283,038$ in 1976 and 2,152,758 in 2013, which was a $67.8 \%$ increase across those 38 years. Population trends in the AI had particularly steady increases (Table B.2, Fig. 3d). Residuals from the nonlinear Gompertz model for Thick-billed Murres correlated positively with those of Common Murres across AK, particularly in the AI and GOA, in addition to those of Black-legged Kittiwakes in the AI.

\subsection{Tufted puffins}

Four of the seven competitive models for Tufted Puffins across AK indicated significant density dependence (Table 2, Fig. 2e). The top model estimated that $\mathrm{K}$ remained constant, at 482,435 across 24 years (1990-2013). Tufted Puffins declined significantly from 1991 to 2013 in the GOA by $47.0 \%$ ( $p<0.001$, Table B.2, Fig. 3e, Fig. 5 ). Residuals from the nonlinear Gompertz model for Tufted Puffins correlated positively with those of common murres in the AI.

Across AK, Tufted Puffins have a 13.72\% (SE = 4.0) chance of falling below 50 individuals, and a $28.5 \%$ ( $\mathrm{SE}=8.0$ ) chance of falling below 500 within the next 100 years. In the GOA, they have a higher probability of falling below $50(34.1 \%, \mathrm{SE}=16.8)$ and $500(38.8 \%, \mathrm{SE}=17.1)$ individuals within the next 30 years. Over the next 100 years in the GOA, we found high probabilities of quasi-extinction (Fig. 5): $82.9 \%\left(\mathrm{~N}_{\mathrm{e}}<50\right.$, $\mathrm{SE}=25.5)$ and $83.1 \%\left(\mathrm{~N}_{\mathrm{e}}<500, \mathrm{SE}=25.6\right)$.

\section{Discussion}

We document significant changes in the carrying capacity of kittiwake, murre and puffin populations in AK, over the past four decades.
Consistent with density dependence, the population sizes of all species in our study fluctuated around their estimated $\mathrm{K}$, such that dips below that threshold were followed by recovery, and increases above $\mathrm{K}$ were followed by drops. It was important that we allow for density dependence in our time-series analysis, because it enabled us to identify long-term increases in $\mathrm{K}$, despite short-term drops in population size. For example, the carrying capacity of murres increased significantly, even in the wake of the 1989 Exxon Valdez oil spill, when their population size dropped. Red-legged Kittiwakes showed decadal population fluctuations around $\mathrm{K}$, which appeared relatively stable. Black-legged Kittiwakes, on the other hand, showed significant decreases in $\mathrm{K}$ across AK, particularly in the four years following the oil spill in the GOA. Colonies in the GOA accounted for the declines in Tufted Puffins. Our PVA suggests that this species may have a probability of extirpation from the small handful of colonies that are monitored in the GOA, within the next 100 years. Had we not modeled density dependence, we may have overestimated the probability of persistence in Tufted Puffins. Our results suggest that conservation efforts should target southern AK to sustain population thresholds that will maintain connectivity of kittiwakes and puffins throughout the North Pacific.

\subsection{Black-legged kittiwakes}

We document significant declines in the $\mathrm{K}$ of Black-legged Kittiwakes across AK, which originated primarily from colonies in the GOA and $\mathrm{AI}$. In the GOA, K decreased by over 80\% from 1989 to 1992, in conjunction with the Exxon Valdez oil spill. However, the impacts of the oil spill are poorly understood, due to confounding factors (e.g., forage availability and climatic shifts) that may have coincidentally affected 

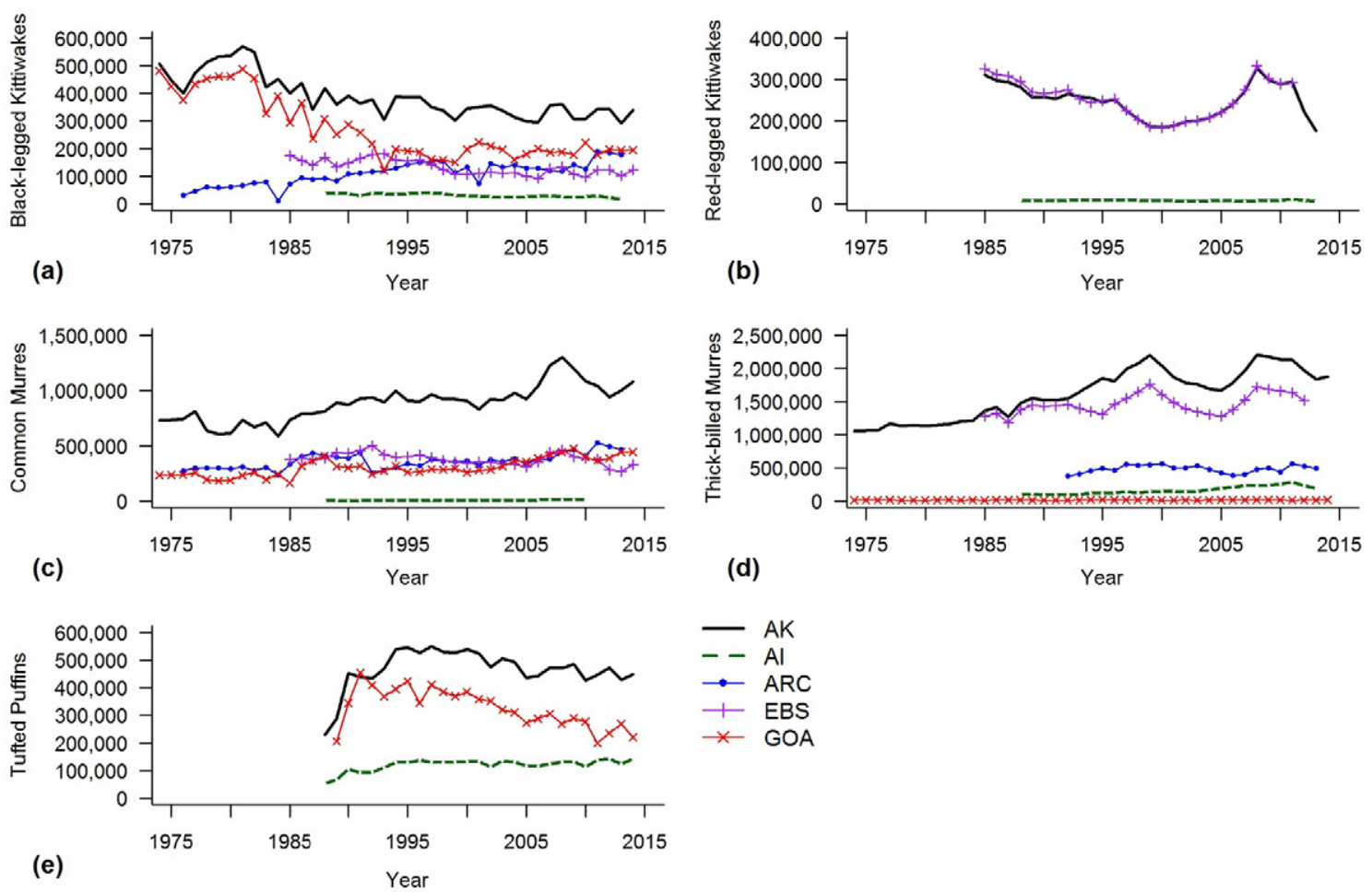

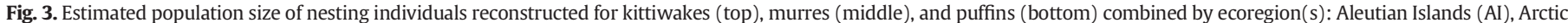
(ARC), Eastern Bering Sea (EBS), Gulf of Alaska (GOA); Alaska (AK) refers to estimates from Fig. 2.

kittiwake foraging distributions (Irons et al., 2000). Black-legged Kittiwakes qualify as K-strategists, yet they showed high mean rates of change that may have helped them cope with an unpredictable environment (Southwood, 1981). Alternatively, density dependence could have led to slow recoveries at low population numbers (e.g., depending on the nature of temporal autocorrelation and/or nonlinearity in the relationship between population size and rates of change; Morris and Doak, 2002; Sibly et al., 2005; Southwood, 1981). Despite the slowing of long-term declines in recent years, Black-legged Kittiwake populations have not recovered to pre-spill levels.

The decreases that we describe in Black-legged Kittiwakes have important conservation implications, especially given their current listing as a species of Least Concern by the IUCN. Our results suggest a $>40 \%$ reduction in $\mathrm{K}$ (Fig. 2a) over three generations in AK (each 12.9 years in length, according to BirdLife International, 2015b). If this Alaskan trend applied to their entire population, the steep decline would support changing the conservation status of Black-legged Kittiwakes in

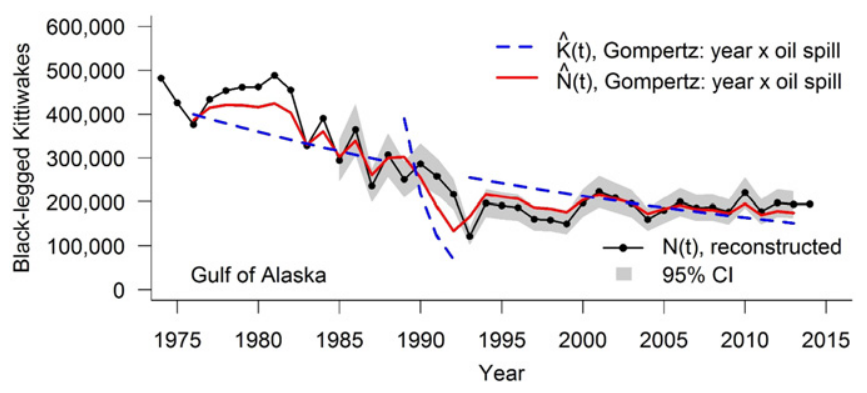

Fig. 4. Most descriptive model of black-legged kittiwake population dynamics at monitored colonies in the Gulf of Alaska. Reconstructed population sizes of nesting individuals, $N(t)$, are shown as black dotted solid lines with $95 \%$ confidence intervals (gray shading). Solid red lines show model-estimated population size, $\hat{N}(t)$, and blue dashed lines indicate model-estimated carrying capacity, $\hat{K}(t)$. This suggests a significant drop in K by 82.3\% from 1989 to $1992(p<0.01)$ following the Exxon Valdez oil spill. the North Pacific to Vulnerable (facing a high risk of extinction in the wild). Furthermore, our PVA suggests an intermediate probability of extirpation from parts of southern AK that sustain low numbers (i.e., AI). However, our results reveal a nonlinear decline in $\mathrm{K}$ across $\mathrm{AK}$, in that it slowed down in recent years. As a result, our forecasts suggest that Black-legged Kittiwakes are not likely to go extinct in AK within the next 100 years, assuming no large deviations from current environmental conditions into the future. In other parts of their circumpolar distribution, this species has displayed density independence along with high probabilities of extinction (Sandvik et al., 2014). Had we not modeled density dependence, estimates of the probability of persistence in Black-legged Kittiwakes would have been highly uncertain and misleading.

\subsection{Red-legged kittiwakes}

Using our estimates of the quasi-global population size of Red-legged Kittiwakes, we identified a stable $\mathrm{K}$ at Buldir (AI) and an increasing $\mathrm{K}$ in the Pribilof Islands (EBS). Our PVA suggests an intermediate probability of persistence in southern AK, due to low numbers in the AI. Nonetheless, the IUCN listing of Red-legged Kittiwakes as "Vulnerable" (BirdLife International, 2015a) remains warranted due to large decadal fluctuations in their population dynamics, particularly in the EBS. These intervals correspond closely to their generation length (12.9 years; BirdLife International, 2015a), but most recently have culminated in a steep decline in their population size from 2008 to 2013. Incorporating vital rates into future analyses may reduce the uncertainty inherent to population forecasts and explain some of this recent volatility.

\subsection{Common and thick-billed murres}

Our correlation analysis of residuals from the model with the most explanatory value suggested that congeners (black and red-legged kittiwakes, common and thick-billed murres) were similarly affected by unexplained variation, presumably generated from demographic or environmental influences. However, the residuals for Common Murres 

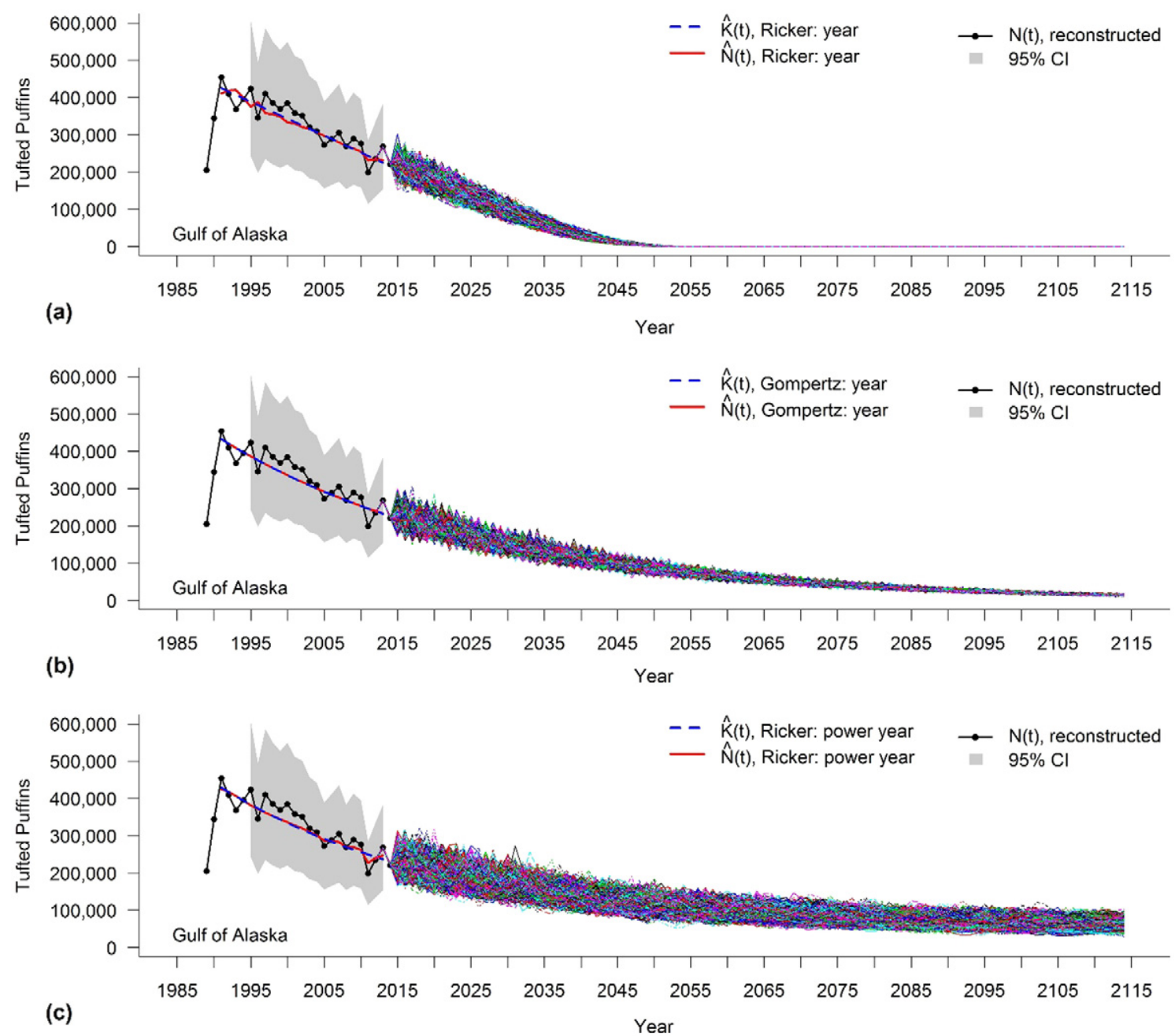

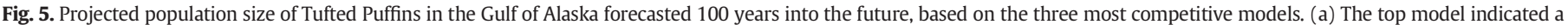
significantly decreasing time trend in carrying capacity, as did (b) the second best model, and (c) the third most competitive model allowed for a nonlinear trend in K.

additionally correlated positively with those of all other species, evidence that they may serve as useful indicators of environmental change in AK (Piatt et al., 2007).

Rates of change in Thick-billed Murres took one extra year to reverse in response to population size and return towards $\mathrm{K}$, leading to wider fluctuations than in the other species (Fig. 2d). Unlike Red-legged Kittiwakes, this lagged response could not be attributed to the sampling regime. It remains unclear what contributed to such delays, but skipped breeding and the nature of density dependence may have played a role. Skipping a year after first breeding is a fairly common strategy for long-lived organisms like murres that face environmental constraints (Gaston and Hipfner, 2000; Reed et al., 2015). Additionally, a nonlinear relationship between rates of change and population size in some bird and mammal species leads to lags from their populations spending more time at or above K than below (Sibly et al., 2005).

Our results suggest significant increases in the $\mathrm{K}$ of both murre species in the AI, and additionally in the ARC and GOA for Common Murres. Following the Exxon Valdez oil spill, the $\mathrm{K}$ of Common Murres in the GOA continued to increase despite drops in their population size (Fig. 3; Piatt and Anderson, 1996), which allowed this species to sustain the event. We expected them to show significant population-level impacts from the spill as a result of high carcass recoveries (Piatt and Ford, 1996; Piatt et al., 1990). However, their populations showed more resilience to environmental change than kittiwakes and puffins. This highlights why it was important for our study to incorporate the novel perspective of density dependence and changing $\mathrm{K}$ across a four-decade long time-series.

\subsection{Tufted puffins}

We provide updated population estimates for Tufted Puffins, and identify a possibility of future extirpation from the colonies monitored in the GOA. Across AK, estimated K for Tufted Puffins was just under 500,000 , suggesting that (1) BSCC numbers may be overestimated (i.e., we sampled $>10 \%$ of the Alaskan population, Table 1 ) or (2) current estimates of the global population size of Tufted Puffins have been underestimated at around 3 million (i.e., we sampled < one seventh of the global population; BirdLife International, 2012; Piatt and Kitaysky, 2002). We document a significant $>40 \%$ decrease in $K$ over 23 years in the GOA (their generation length is 21.6 years; BirdLife International, 2012), where our PVA projects that Tufted Puffin populations may fall below 50 individuals within the next century.

Our Tufted Puffin projections should be treated with caution, however, because of difficulties in their population monitoring compared to kittiwake and murres. First, because of the difficulty in monitoring burrow-nesting species, our Tufted Puffin analyses are based on just a small proportion of the whole population. Population trend data existed for just 8 sites (out of hundreds of Tufted Puffin colonies in Alaska) that comprise just about $10 \%$ of the state population; furthermore, at these sites, only about $5 \%$ of burrows were actually surveyed. (In comparison, 
kittiwake and murre population data come from colonies that make up $40-100 \%$ of estimated Alaskan populations [AMNWR unpubl. data]). In addition, there is some concern that the methods used in Tufted Puffin monitoring (e.g., reaching arms into burrows or digging holes into tunnels for better nest access) can cause substantial disturbance (Pierce and Simons, 1986) and may be influencing populations at monitored colonies in Alaska (A. Kettle and L. Slater, pers. comm.). This is in marked contrast to the relatively-unobtrusive observation methods of monitoring cliff-nesting kittiwake and murres from a distance. It is possible, therefore, that population declines we documented at the few monitored colonies in Alaska may not necessarily represent the whole population.

Even if our projected Tufted Puffin population decline may be inflated, there is still reason for concern, as the species has shown declines in multiple large marine ecosystems in eastern Pacific boundary currents, including British Columbia, Canada, and the U.S. Pacific Northwest (Gaston et al., 2009; Piatt and Kitaysky, 2002). The distinct population segment of Tufted Puffins for the California Current has been proposed for listing under the ESA (Hodum, 2013), with the USFWS finding that the petition is warranted for a full status review. Further research should identify the genetic structure of Tufted Puffin populations to address metapopulation connectivity and to determine the minimum viable population sizes necessary to prevent inbreeding depression (Frankham et al., 2014). Our results suggest that future management action should focus on colonies in southern AK, and place particular attention on climate change, to maintain population connectivity throughout their global range.

\subsection{Environmental variability}

Our PVAs operate under the assumption that current conditions will persist into the next century, but the prospect of climate change adds a large degree of uncertainty to any forecast. Explicitly modeling climatological factors may help to explain large regime shifts. Paleczny et al. (2015) have reported 70\% declines of seabirds monitored world-wide, citing climate change as a primary global threat. Evidence suggests that circumpolar changes in the abundance of Common and Thick-billed Murres are sensitive to climate-induced changes in sea surface temperature (Irons et al., 2008). Our results are consistent with preliminary studies showing global declines in Black-legged Kittiwakes that are strongly coupled with the rapid warming of the oceans (Descamps et al., unpublished data). In our study, kittiwakes and Common Murres show sensitivity to similar environmental influences (or other factors extraneous to our models) in the EBS, but not in the GOA. As surface feeders, kittiwakes may be more limited by offshore forage availability than murres, which have the flexibility to access prey at considerable depth. Climate-induced changes in nearshore forage availability may also impact Tufted Puffins, and exacerbate threats of bycatch from the gillnet fishery (Gjerdrum et al., 2003; Žydelis et al., 2013). Thus, it is important to closely monitor the continuing dynamics of kittiwakes and puffins together with changes in their habitat and climate, particularly in southern AK.

Future research should include additional demographic factors (e.g. survival, reproductive success, Renner et al., 2014), as well as habitat covariates, to explain environmental influences on the dynamics of population change that we have observed. Site fidelity is strong in all five of our study species (Ainley et al., 2002; Byrd and Williams, 1993; Gaston and Hipfner, 2000; Hatch et al., 2009; Piatt and Kitaysky, 2002), minimizing interannual fluctuations in the distributions of birds among colony sites. However, more broad-scale analyses are needed to identify potential population sources or sinks ascribed to the influences of habitat or between-colony dispersal. Further research should expand on why kittiwake and murre populations have both increased in the ARC, but have responded differently from each other to conditions in the GOA and AI. Among the complex ecosystems that comprise $\mathrm{AK}$, it is necessary to describe population dynamics both within and between regions. Large scale analyses are important in determining the conservation status of species, and identifying the sources of change at a regional scale helps to direct management and recovery efforts.

Evaluating the ecosystem-wide drivers of population dynamics, in the context of density dependence, is fundamental to explaining changes in K. Density dependence can help to prevent population crashes (e.g., from catastrophic events) by sustaining a declining population's probability of persistence in the long term. This is because populations are likely to recover, at least in the short-term, once they fall below $\mathrm{K}$. However, species may respond to a catastrophe in different ways, due to their life history parameters. In K-strategists, an environmental perturbation may cause relatively short-term (e.g., 1-4 year) populationlevel impacts without influencing K (May, 1981). Yet, when such a disturbance occurs in conjunction with other forces (e.g., human-related take), it could slow recoveries by altering $\mathrm{K}$. Long-term impacts are further exacerbated by autocorrelation, which holds populations at low numbers, triggering severe acceleration of declines in $\mathrm{K}$ (Morris and Doak, 2002). The focus of wildlife managers is often to augment the number of individuals that a region supports (i.e., K) by improving its habitat quality. Additionally important, but undervalued, is the need to estimate the magnitude of population fluctuations around a changing $\mathrm{K}$ so as to maintain the population above thresholds necessary to conserve declining populations.

\section{Role of the funding source}

Funding was provided by the USFWS, (4500079559) Natural Resource Program Center. Sponsors of this study provided financial support, and were not involved in the study design, collection, analysis, interpretation of data, or submission of this manuscript. The findings and conclusions in this article are those of the author(s) and do not necessarily represent the views of the U.S. Fish and Wildlife Service.

\section{Acknowledgments}

We are grateful for funding assistance from Aaron Poe (Aleutian and Bering Sea Islands Landscape Conservation Cooperative) and Courtney Conway (ID Coop. Fish \& Wildlife Research Unit). We thank several data contributors, including: past and present AMNWR biologists (especially Marc Romano, Leslie Slater, Nora Rojek, Don Dragoo, Arthur Kettle, Jeff Williams), the U.S. Fish and Wildlife Service (USFWS) office of Migratory Birds Management: Dave Irons, Lisa Sheffield; AK Peninsula/ Becharof NWR: Melissa Cady; Togiak NWR: Patrick Walsh; Yukon Delta NWR: Brian McCaffery; U.S. Geological Survey (USGS): Scott Hatch; AK Department of Fish and Game (ADF\&G): Ed Weiss; University of AK, Fairbanks: Ed Murphy, Dean Kildaw. We appreciate statistical input from Jon Horne (ID F\&G) and Aaron Christ (AMNWR). We thank two anonymous reviewers, Marius Myrvold, Amanda Goldberg, and Eamon Harrity for manuscript comments.

\section{References}

Ainley, D.G., Nettleship, D.N., Carter, H.R., Storey, A.E., 2002. In: Poole, A. (Ed.), Common murre (Uria aalge). Cornell Lab of Ornithology, Ithaca, NY Retrieved from the Birds of North America Online:. http://bna.birds.cornell.edu/bna/species/666.

BirdLife International, 2012. Fratercula cirrhata. The IUCN Red List of Threatened Species E.T22694934A38912055 . http://dx.doi.org/10.2305/IUCN.UK.2012-1.RLTS.T22694934A 38912055.en.

BirdLife International, 2015a. Rissa brevirostris. The IUCN Red List of Threatened Species E.T22694502A84733728 . http://dx.doi.org/10.2305/IUCN.UK.2015.RLTS.T22694502A 84733728.en. 
BirdLife International, 2015b. Rissa tridactyla. The IUCN Red List of Threatened Species. E.T22694497A38874175 . http://dx.doi.org/10.2305/IUCN.UK.2012-1.RLTS.T2269 4497A38874175.en.

Burnham, K.P., Anderson, D.R., 2002. Model Selection and Multimodel Inference: A Practical Information-Theoretic Approach. Springer, New York, NY.

Byrd, G.V., 1989. Seabirds in the Pribilof Islands, Alaska: Trends and Monitoring Methods. University of Idaho.

Byrd, G.V., Williams, J.C., 1993. In: Poole, A. (Ed.), Red-legged kittiwake (Rissa brevirostris) Cornell Lab of Ornithology, Ithaca, NY Retrieved from the Birds of North America Online:. http://bna.birds.cornell.edu/bna/species/060.

Byrd, V.G., Renner, H.M., Renner, M., 2005. Distribution patterns and population trends of breeding seabirds in the Aleutian Islands. Fish. Oceanogr. 14,139-159.

Byrd, G.V., Schmutz, J.A., Renner, H.M., 2008. Contrasting population trends of piscivorous seabirds in the Pribilof Islands: a 30-year perspective. Deep-Sea Res. II Top. Stud. Oceanogr. 55, 1846-1855.

Conroy, M.J., Carroll, J.P., 2009. Quantitative Conservation of Vertebrates. Wiley-Blackwell, Hoboken, NJ.

Croxall, J.P., Butchart, S.H.M., Lascelles, B.E.N., Stattersfield, A.J., Sullivan, B.E.N., Symes, A. Taylor, P., 2012. Seabird conservation status, threats and priority actions: a global assessment. Bird Conserv. Int. 22, 1-34.

Denlinger, L.M., 2006. Alaska Seabird Information Series. U.S. Fish and Wildlife Service, Migratory Bird Management, Nongame Program, Anchorage, AK.

Dennis, B., Taper, M.L., 1994. Density dependence in time series observations of natura populations: Estimation and testing. Ecol. Monogr. 64, 205-224.

Dennis, B., Ponciano, J.M., Lele, S.R., Taper, M.L., Staples, D.F., 2006. Estimating density dependence, process noise, and observation error. Ecol. Monogr. 76, 323-341.

R Development Core Team, 2014. R: A Language and Environment for Statistical Computing, Version 3.0.3. R Foundation for Statistical Computing, Vienna, Austria. http:// www.R-project.org.

Dragoo, D.E., Renner, H.M., Irons, D.B., 2015. Breeding status and population trends of seabirds in Alaska, 2014. U.S. Fish and Wildlife Service Report AMNWR 2015/03, Homer AK.

Frankham, R., Bradshaw, C.J.A., Brook, B.W., 2014. Genetics in conservation management: Revised recommendations for the 50/500 rules, Red List criteria and population viability analyses. Biol. Conserv. 170, 56-63.

Franklin, I.R., 1980. Evolutionary change in small populations. In: Soule, M.E., Wilcox, B.A. (Eds.), Conservation Biology: An Ecological-Evolutionary Perspective. Sinauer Associates, Sunderland, MA, pp. 135-139.

Garton, E.O., Connelly, J.W., Horne, J.S., Hagen, C.A., Moser, A., Schroeder, M., 2011. Greater sage-grouse population dynamics and probability of persistence. In: Knick, S.T. Connelly, J.W. (Eds.), Ecology and Conservation of Greater Sage-Grouse: A Landscape Species and Its Habitats. Studies in Avian Biology 38. University of California Press, Berkeley, CA, pp. 293-381.

Garton, E.O., Hagen, C.A., Beauprez, G.M., Kyle, S.C., Pitman, J.C., Schoeling, D., Van Pelt, W.E., 2016. Population dynamics of the lesser prairie-chicken. In: Haukos, D.A. Boal, C.W. (Eds.), Ecology and conservation of Lesser Prairie-chicken. Studies in Avian Biology 48. CRC Press, Boca Raton, FL, pp. 49-76.

Gaston, A.J., Hipfner, J.M., 2000. In: Poole, A. (Ed.), Thick-billed murre (Uria lomvia). Cornell Lab of Ornithology, Ithaca, NY Retrieved from the Birds of North America Online: http://bna.birds.cornell.edu/bna/species/497.

Gaston, A.J., Bertram, D.F., Boyne, A.W., Chardine, J.W., Davoren, G., Diamond, A.W., Hedd, A., Montevecchi, W.A., Hipfner, J.M., Lemon, M.J.F., Mallory, M.L., Rail, J.-F., Robertson, G.J., 2009. Changes in Canadian seabird populations and ecology since 1970 in relation to changes in oceanography and food webs. Environ. Rev. 17, 267-286.

Gjerdrum, C., Vallée, A.M.J., St. Clair, C.C., Bertram, D.F., Ryder, J.L., Blackburn, G.S., 2003. Tufted puffin reproduction reveals ocean climate variability. Proc. Natl. Acad. Sci. 100, 9377-9382

Hatch, S.A., Robertson, G.J., Baird, P.H., 2009. In: Poole, A. (Ed.), Black-legged kittiwake (Rissa tridactyla). Cornell Lab of Ornithology, Ithaca, NY Retrieved from the Birds of North America Online:. http://bna.birds.cornell.edu/bna/species/092.

Hodum, P.J., 2013. Consideration of the California/Oregon/Washington population of the Tufted Puffin (Fratercula cirrhata) as a distinct population segment under the U.S. Endangered Species Act. Submitted as Part of a Petition by the Natural Resources Defense Council (NRDC) to the U.S. Fish and Wildlife Service . http://ecos.fws.gov/ ecp0/profile/speciesProfile?sId $=430$.

Hunt, G.L., Eppley, Z.A., Schneider, D.C., 1986. Reproductive performance of seabirds: The importance of population and colony size. Auk 103, 306-317.

Irons, D.B., Anker-Nilssen, T., Gaston, A.J., Byrd, G.V., Falk, K., Gilchrist, G., Hario, M., Hjernquist, M., Krasnov, Y.V., Mosbech, A., Olsen, B., Petersen, A., Reid, J.B.,
Robertson, G.J., Strøm, H., Wohl, K.D., 2008. Fluctuations in circumpolar seabird populations linked to climate oscillations. Glob. Chang. Biol. 14, 1455-1463.

Irons, D.B., Kendall, S.J., Erickson, W.P., McDonald, L.L., Lance, B.K., 2000. Nine years after the "Exxon Valdez" oil spill: effects on marine bird populations in Prince William Sound, Alaska. Condor 102, 723-737.

Koeppen, W., Kuletz, K., Poe, A., Renner, H., Smith, M., Pelt, T.V., Walker, N., Williams, J., 2015. Exploring Vulnerabilities of Seabirds Using Projected Changes in Climate in the Aleutian Islands and Bering Sea. Aleutian-Bering Sea Islands Landscape Conservation Cooperative.

May, R.M., 1981. Models for single populations. In: May, R.M. (Ed.), Theoretical Ecology. Sinauer Associates, Inc., Sunderland, Massachusetts, pp. 5-29.

Mills, L.S., 2012. Conservation of Wildlife Populations: Demography, Genetics, and Management. second ed. Wiley-Blackwell, Hoboken, NJ.

Morris, W.F., Doak, D.F., 2002. Quantitative Conservation Biology: Theory and Practice of Population Viability Analysis. Sinauer Associates, Sunderland, MA USA

Paleczny, M., Hammill, E., Karpouzi, V., Pauly, D., 2015. Population trend of the world's monitored seabirds, 1950-2010. PLoS One 10, e0129342.

Peterson, C.H., Rice, S.D., Short, J.W., Esler, D., Bodkin, J.L., Ballachey, B.E., Irons, D.B., 2003. Long-term ecosystem response to the Exxon Valdez oil spill. Science 302, 2082-2086.

Piatt, J.F., Anderson, P., 1996. Response of common murres to the Exxon Valdez oil spill and long-term changes in the Gulf of Alaska marine ecosystem. American Fisheries Society Symposium, pp. 720-737.

Piatt, J.F., Ford, R.G., 1996. How many seabirds were killed by the Exxon Valdez oil spill. American Fisheries Society Symposium, pp. 2-5.

Piatt, J.F., Kitaysky, A.S., 2002. In: Poole, A. (Ed.), Tufted Puffin (Fratercula cirrhata). Cornell Lab of Ornithology, Ithaca, NY Retrieved from the Birds of North America Online: http://bna.birds.cornell.edu/bna/species/708

Piatt, J.F., Harding, A.M.A., Shultz, M., Speckman, S.G., van Pelt, T.I., Drew, G.S., Kettle, A.B., 2007. Seabirds as indicators of marine food supplies: cairns revisited. Mar. Ecol. Prog. Ser. 352, 221-234.

Piatt, J.F., Lensink, C.J., Butler, W., Marshal, K., Nysewander, D.R., 1990. Immediate impact of the 'Exxon Valdez' oil spill on marine birds. Auk 107, 387-397.

Pierce, D.J., Simons, T.R., 1986. The influence of human disturbance on tufted puffin breeding success. Auk 103, 214-216.

Reed, T.E., Harris, M.P., Wanless, S., 2015. Skipped breeding in common guillemots in a changing climate: restraint or constraint? Front. Ecol. Evol. 3.

Renner, H.M., Drummond, B.A., Benson, A.-M., Paredes, R., 2014. Reproductive success of kittiwakes and murres in sequential stages of the nesting period: Relationships with diet and oceanography. Deep-Sea Res. II Top. Stud. Oceanogr. 109, 251-265.

Sandvik, H., Reiertsen, T.K., Erikstad, K.E., Anker-Nilssen, T., Barrett, R.T., Lorentsen, S.H., Systad, G.H., Myksvoll, M.S., 2014. The decline of Norwegian kittiwake populations: modelling the role of ocean warming. Clim. Res. 60, 91-102.

Scheaffer, R., Mendenhall III, W., Ott, L., 1996. Elementary Survey Sampling. fifth ed. Duxbury Press, New York, NY.

Sibly, R.M., Barker, D., Denham, M.C., Hone, J., Pagel, M., 2005. On the regulation of populations of mammals, birds, fish, and insects. Science 309, 607-610.

Slater, L., Byrd, G.V., 2009. Status, trends, and patterns of covariation of breeding seabirds at St Lazaria Island, Southeast Alaska, 1994-2006. J. Biogeogr. 36, 465-475.

Smith, M.A., Walker, N.J., Free, C.M., Kirchhoff, M.J., Drew, G.S., Warnock, N., Stenhouse, I.J., 2014. Identifying marine important bird areas using at-sea survey data. Biol. Conserv. 172, 180-189.

Smith, M.A., Walker, N.J., Free, C.M., Kirchhoff, M.J., Warnock, N., Weinstein, A., Distler, T., Stenhouse, I.J., 2012. Marine Important Bird Areas in Alaska: Identifying globally Significant Sites Using Colony and At-sea Survey Data. Audubon Alaska, Anchorage, AK.

Soulé, M.E., 1980. Thresholds for survival: maintaining fitness and evolutionary potential. In: Soule, M.E., Wilcox, B.A. (Eds.), Conservation Biology: an Ecological-Evolutionary Perspective. Sinauer Associates, Sunderland, MA, pp. 151-169.

Southwood, T.R.E., 1981. Binomic strategies and population parameters. In: May, R.M. (Ed.), Theoretical Ecology. Sinauer Associates, Inc., Sunderland, Massachusetts, pp. 30-52.

Turchin, P., 1999. Population regulation: a synthetic view. Oikos 153-159.

Wooller, R.D., Bradley, J.S., Croxall, J.P., 1992. Long-term population studies of seabirds. Trends Ecol. Evol. 7, 111-114.

Žydelis, R., Small, C., French, G., 2013. The incidental catch of seabirds in gillnet fisheries: a global review. Biol. Conserv. 162, 76-88. 